\title{
Integration of Pedagogical and Production Factors in the Process of the Formation of Industry 4.0
}

\author{
Nikolay Chapaev ${ }^{1}$, Olga Akimova ${ }^{1}$, Yevgeniy Dorozhkin ${ }^{1}$, \\ Andrey Efanov ${ }^{2}$, Ekaterina Bychkova ${ }^{2}$

\begin{abstract}
${ }^{1}$ Department of Vocational Education and Training Methodology, Russian State Vocational Pedagogical University, Mashinostroiteley, 11, Yekaterinburg, 620143, Russia Vocational Pedagogical University, Mashinostroiteley, 11, Yekaterinburg, 620143, Russia
\end{abstract} \\ ${ }^{2}$ Department of Economics, Management, Marketing and Technologies of Economic Education, Russian State
}

\begin{abstract}
The rapid development of Industry 4.0 as a result of the Fourth Industrial Revolution brings back the relationship of pedagogy and production to mutual integration that has been their characteristic since ancient times. The study revealed high digital readiness of students (4.24 according to the student assessment and 2.82 according to the teacher assessment on a 5point scale) and very low readiness of production to accept integrated learning (1.68 and 2.67, respectively), as well as the poor digitalization of the educational process according to the students and teachers, who are more closely familiar with the reality of production (2.03 and 2.45, respectively).
\end{abstract}

Keywords - digital environment, Industry 4.0, digital learning, integrated learning

\section{Introduction}

Industry 4.0 , initiated by the German government at the 2011 Hannover Industrial Fair, is developing at a very fast pace.

DOI: 10.18421/TEM104-62

https://doi.org/10.18421/TEM104-62

Corresponding author: Nikolay Chapaev,

Department of Vocational Education and Training Methodology, Russian State Vocational Pedagogical University, Yekaterinburg, Russia.

Email: chapaevnik82@rambler.ru

Received: 04 August 2021.

Revised: 11 November 2021.

Accepted: 17 November 2021.

Published: 26 November 2021.

(cc) BY-NC-ND (C) 2021 Nikolay Chapaev et al; published by UIKTEN. This work is licensed under the Creative Commons Attribution-NonCommercial-NoDerivs 4.0 License.

The article is published with Open Access at www.temjournal.com
It is the integration of a rapidly evolving digital environment encompassing everyday life, the repletion of wants, infrastructure management, communications, manufacturing, and industrial production. Three preliminary phases of the industrial revolution are considered: the industrial revolution itself, the digital revolution with the advent of computer technologies, the communication revolution, and the Fourth Industrial Revolution that completes it. The latter is most often defined as the penetration of cyber-physical systems into production [1]. The result of the Fourth Industrial Revolution is the formation of Industry 4.0, which is characterized by the group of technologies defining it: big data analytics, the use of the Internet of things, the use of virtual and augmented reality, quantum computing, autonomous technology that can make decisions independently, blockchain technology [1].

At the moment, this industry does not yet exist; however, many researchers note that it requires most of these technologies to be integrated and merged in a single infrastructure, which has not yet been observed [2], [3]. On the other hand, extensive changes in all spheres of human life lead to the emergence and integration of a number of elements of Industry 4.0, which creates a common global infrastructure [1].

The availability of a highly professional staff is crucial for Industry 4.0. Due to the fact that production management becomes intelligent and most decisions are made by machines, a person must be well trained to form a strategy, anticipate and balance unpredictable or extreme situations, contribute to the development of production, and competently select solutions offered by artificial intelligence based on the analysis of big data [4], [5]. In the past, on-the-job training and the integration of education and production were important factors in the training of specialists who started working immediately after graduation; today, the integration 
of pedagogy and production is a necessity of survival. The pace of technological changes and knowledge accumulation does not allow separating education and its practical application due to the obsolescence of knowledge and technology [6].

In the earliest primitive society, there were three interdependent parallel processes: the formation of human society (man), the formation of human tool activity, and the formation of human educational activity. The heart of primitive syncretism is the harmonious unity of pedagogical and production processes. The production of things and the production of people as social subjects constituted one syncretic whole. That is, the pedagogical and production processes were inseparable. A member of the primitive society learned by producing and produced while learning [7]. Thus, pedagogical integration is not something completely new in the history of mankind.

In the second development phase (the inception of pedagogical ideas), pedagogy is separated from production; the educational and production processes are sorted out within the homogenized human activity. Pedagogical and technical knowledge lost its ontological unity, which was common within the framework of syncretic activity [8].

As a result, the divergence of the syncretism of teaching and production took place. Pedagogy and production, that is, pedagogical and technical skills, are becoming relatively autonomous spheres of human activity. At the same time, the lack of systematized theoretical foundations of education during the period under consideration should be noted. They were laid down and developed in the third phase of the development of pedagogy, the stage of pedagogy functioning as an independent scientific discipline (first quarter of the 17th century the present) [7]. The emergence of pedagogy as an independent scientific discipline contributed to the systematic development of the theoretical foundations of pedagogy as an integral system of scientific knowledge that covers the problems of scientific substantiation of the professional development of a person based on labor education. When considering these problems, researchers dealt with the interaction of pedagogical and production factors in one way or another, directly or indirectly [9], [10].

Today, we are observing the reverse integration of pedagogy and production at a new stage of development. At the same time, it is obvious that in the process of the formation of Industry 4.0, individual countries and regions have divergent degrees of readiness for such integration, which is associated with the history of the pedagogical systems of different countries and dissimilar rates of technological development or technology acquisitions [11], [12]. The purpose of the study is to assess the readiness for the integration of the pedagogical and production processes from the perspective of their participants, students, and teachers, as well as to determine the process components that should be considered critical in the context of developing countries.

\section{Literature Review}

Generally, the research on the development of Industry 4.0 tends to consider the pedagogical component of the technology as one of the most significant elements [13]. At the same time, a student or any person studying to participate in the production process must have a high level of digital literacy. It includes the ability to handle mobile devices, proficient computer skills, basic knowledge of programming, the ability to use databases, and computer graphics and modeling, as well as communication capabilities of the Internet [14].

A number of researchers are trying to identify groups of competencies that could become predictors of the possibility of harmonious integration of education and production in Industry 4.0 [12]. There are various groups of such competencies; however, all of them distinguish a group of digital and communicative competencies associated with the use of the digital environment; a group of professional competencies related to the ability to obtain professional information, accumulate and analyze it in the process of learning throughout life; a group of competencies closely related to the penetration of digital technologies into teaching and a group of competencies related to the readiness of production to accept and train Industry 4.0 specialists [15], [16]. In this particular case, the readiness of the production sector is crucial; thus, in addition to its own extensive digital infrastructure, the use of virtual reality elements, 3D printing or big data analysis in production, it should also assume the possibility of integrating certain components of production management into training networks. On the one hand, this allows adjustments of some units to the needs of students, and, on the other hand, ensures an easy and efficient exchange of information between the university and production, assesses the work of students, monitors their activities, and immediately offers them assistance in solving production problems [17], [18].

According to researchers from many countries, learning factories meet these requirements; they combine training and production in a way that allows performing real production functions [12], [19]. Today, many industries are actively creating such factories as separate production facilities or specialized lines, where experienced engineers and 
experts can teach students, in fact, without interrupting production. This approach to business also reduces the costs of training specialists as it partly pays off directly in the production process [13].

The research on virtual and augmented reality is moving towards the use of these mechanisms to manage complex and multidimensional production processes based on sensor systems and big data processing, as well as to make training as close to reality as possible [20]. Currently, these technologies are the most technologically dependent and require substantial investment, but they also most naturally integrate the educational process and industrial internship as working in virtual reality can be completely identical to the workflow [21].

Researchers consider the integration of pedagogy and production mainly from the perspective of the STEM methodology, that is, a physical contact with engineering objects, the introduction of objective real life problems directly into the educational process, modeling of a similar decision-making process, solving engineering problems within online training and virtual reality or three-dimensional models of production facilities [22].

We have not been able to find studies devoted to the readiness of students to switch to the integrated approach that combines learning and production, which will obviously become natural for Industry 4.0. Most authors consider the high level of penetration of digital reality into all spheres of life as a natural predictor of the harmonious integration of pedagogy and production within the framework of the Fourth Industrial Revolution. However, numerous studies call this into question as even in developed countries, the formation of Industry 4.0 is rather painful [23], [24], [25]. Our research aims to eliminate this research gap in relation to Russia, and the results of the study can be applied to a number of developing countries having similar problems.

\section{Method}

The study involved 226 third-year students (111 women and 115 men) of various fields of study of Russian State Vocational Pedagogical University, Ekaterinburg, Russia, as well as 68 teachers (34 men and 34 women). The participants were invited to voluntarily take part in the study by placing an advertisement on social networks, in educational institutions and academic departments. The respondents completed the questionnaire indicating the value of their assessment of each parameter on the 5-point Likert scale, where 0 is the lack of a feature and 5 is its greatest manifestation.

The questionnaire was compiled on the basis of the most significant parameters of the transition to training in the context of Industry 4.0. These parameters were extracted based on the analysis of the research literature [5], [23], [26], similar studies on the integration of pedagogical and production factors in the training of specialists. The factors affecting the transition are as follows: assessment of one's own actual knowledge (professional knowledge; real production skills), assessment of the readiness of the production environment for the integration with the educational process and pedagogical requirements (production practices; readiness of the production environment for the acceptance of students), assessment of the interaction with the digital environment (ability to work in a digital environment; the current level of penetration of the digital environment into the educational process), assessment of career prospects (willingness to work within the specialty for a relatively long period of time; willingness to change profession in the future). Students assessed their own parameters; teachers assessed the parameters of students.

The assessments given by the survey participants were averaged out and the standard deviation between them was calculated. Student and teacher assessments were analyzed separately (Figure 1.).

No personal data of the participants were recorded or used in the study.

The questionnaires were processed in SPSS Statistics 22 and the analytical data were visualized in MS Excel 2013.

\section{Findings}

The results of the study show that students and teachers have similar assessments of the readiness for the transition to training in the context of Industry 4.0. In particular, despite the fact that teachers generally give a lower assessment of professional knowledge of students (3.01 - teachers, 3.12 students), the difference between the assessments falls within the statistical error while the assessment of real production skills (2.15 - both groups) is identical. Moreover, both groups of respondents noted that practical skills were poorer than the theoretical ones; they were assessed as below average, which indicates the lack of practical use of knowledge and its sporadic application.

Students gave a very low assessment of their possibility to face real production processes before graduating from university (1.14) compared to teachers, whose assessment of the parameter was a bit higher; apparently, this was due to the content of the senior curriculum, which the third-year students have not yet studied (1.87). It should be emphasized that it is not just business processes that are assessed, but also the application of skills and participation in Industry 4.0 with due regard to its digital component. 
Both groups of respondents noted the extremely low availability of such technologies in the Russian education system. At the same time, both groups gave a much higher assessment of the work in a digital environment. The students gave this parameter 4.24 points and teachers - 2.89. Similar studies show that student assessment is associated with the habit of constant use of electronic devices and constant access to information. This situation creates a specific misconception about "natural professionalism" in the field of digital technologies among students, especially those studying engineering. This idea is not correct. Teacher assessment is based on the real experience of using digital technologies in the classroom and industrial internship; therefore, it is noticeably lower.

Both students and teachers assessed the second parameter related to the readiness of the production environment for the acceptance of students to participate in production processes involving digital content, robotization and automation as very low (1.69 - students and 2.67 - teachers). In fact, both groups believe that the production environment is not ready to integrate with pedagogy and fulfill its requirements.

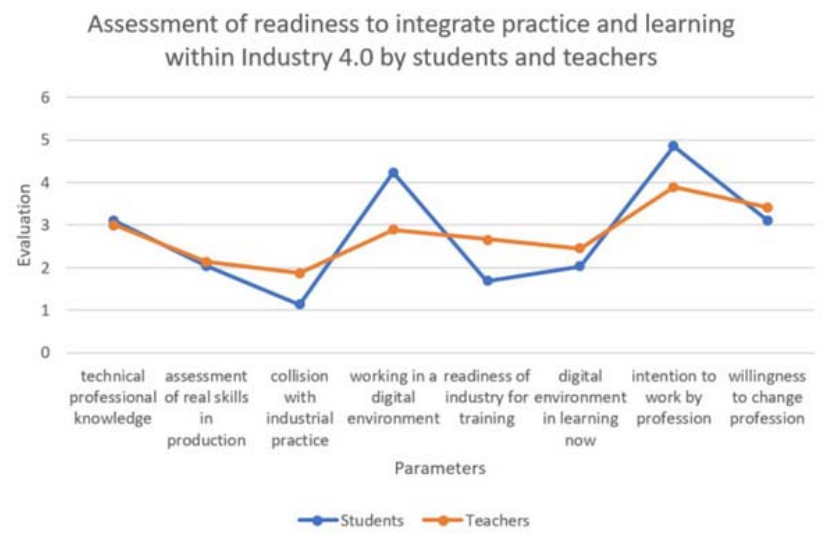

Figure 1. Assessment of readiness to integrate practice and learning within Industry 4.0 by students and teachers

Figure 1. also shows that the career factor in engineering is assessed as very high by all participants. Students noted their readiness to work over a long period of time (4.85) while the teacher assessment was a bit lower (3.89). The reason for this is a question that requires further research. One of the hypotheses is a more realistic assessment of the abilities and personal capabilities of students. The parameter of the readiness to change profession turned out to be unexpectedly high (3.42 - students and 3.12 - teachers). That is, teachers also realize that a great number of students will be involved in engineering only for some period of time, or may not work in this area at all. It should be noted that this is natural in the context of Industry 4.0 and has been observed for some time in many developed countries.
It should also be noted that the student and teacher assessments of professional skills, real production skills, the penetration of the digital environment in education, and the readiness to change jobs in the future fall within the statistical error (which can be observed in Figure 1.). In general, the volatility of student assessments is much higher than that of the teachers (1.14 - 4.85 and $1.87-3.89$, respectively); this indicates greater students' subjectivity given the exact match of the assessments of those parameters that can be more accurately evaluated.

It can be concluded that both students and teachers consider the readiness to integrate pedagogy and production in the process of training Industry 4.0 specialists rather low. The major reason for this is the ill-preparedness of the production sector, which, according to students, is not ready from the technical perspective - in terms of the level of penetration of the digital environment into production and the use of integration to train personnel. At the same time, the readiness of the digital environment and the quality of its development have been assessed as high. The relatively low (average, 3 out of 5) assessment of the parameters related to student knowledge and training are largely associated with the problems of integrating learning with production.

\section{Discussion}

In most cases, researchers study the integration of pedagogy and production in the context of the formation of Industry 4.0 describing the key approaches to the development of continuous end-toend professional training. Learning factories (LF) are the most common; they involve a real production environment focused both on the production of goods entering the market, and at the same time, student and personnel training [12], [27]. Learning factories emerge as independent training facilities based on the combination of the interests of universities and businesses or as partly isolated production incubators for training personnel separately taken out or separated in the production process. Their key feature is constant operation. In this case, students are the employees of the enterprise, where they simultaneously study acquiring both basic professional skills and education [14].

The use of game-based methods, which make it possible to simulate real production processes in a computer game environment that is acceptable and familiar to most modern young people, is being actively discussed. Techniques for creating virtual and augmented reality are increasingly being implemented to most fully simulate a real production environment [22]. The great benefit of virtual simulation is the possibility to practise behavior patterns and decision-making in extreme or 
unpredictable circumstances. This contributes to real-world decision-making, responsibility development, and a deeper understanding of the features of the digital production environment [28].

As noted earlier, the availability of a highly professional staff that have a number of competencies is crucial for Industry 4.0. The most important of them are digital (the ability to use gadgets, process large amounts of information and use databases; analytical skills; high digital literacy) and professional (proficiency in technological processes; extensive theoretical knowledge and constant training; professional erudition; knowledge of the techniques and technologies applied, etc.) competencies [29], [30]. The researchers often note the importance of communicative competencies, which is associated with several production needs: the management of and interaction with highly professional personnel; the search for and use of information to solve real-world problems immediately; the interaction with experts and specialists in related fields. It should be noted that in most developing countries, where the formation of Industry 4.0 is being impeded and dependent on foreign investment [31], communication skills are not yet as important as in developed economies with powerful digital and automated production capacities. Many researchers note that in developing countries and market leading economies, such as China, Turkey, and India, a significant part of production is still based on manual labor that requires various skills, and people trained at the workplace can be involved in production processes [24]. The present study also shows that Russia is among those countries that are characterized by automated production facilities, the widespread use of drones and other elements that are included in the definition of Industry 4.0 technologies; however, at the same time, low-skilled labor is rather common [4].

The possibility of the active training of low-skilled workers directly at the workplace is also part of the fusion of pedagogy and production [32]. In the case of Industry 4.0, there is not a need to be ready to manage a simple or more complex mechanism, but to interact with the digital environment, which makes most of the decisions independently or offers the human operator solution options [19]. According to researchers, the process is effective when several requirements are met. The key ones are the digital literacy of the employee and the relevant college or university degree. This requirement is due to the fact that the employee should be well aware of a large amount of information and knowledge related not only to the area of expertise, but to the fields associated with it. Thus, a programmer must be proficient in mathematics, algorithmic analysis, design theory (for creating user interfaces), etc. [29].
The research describes a situation that, as different foreign studies indicate, is not typical only for Russia, but generally for most actively developing countries that attract significant foreign investment and are the donors of labor resources [24], [31]. As a rule, such countries rely on the reallocation of production facilities to their territory to accelerate their own development and training of qualified personnel, as evidenced by the example of China, India, Turkey, Mexico and the countries of Southeast Asia. In this case, we can observe the readiness of personnel for training, high work motivation (Fig.1. the indicators of the readiness to be involved in engineering), digital literacy, and the penetration of digital technologies and mobile gadgets into society [28], [25], [33]. At the same time, there is a low level of digitalization of production and autonomy of production lines, as well as poor digital infrastructure that ensures the integrated operation of production facilities [4]. In this case, the integration of pedagogy and production is relatively slower as pedagogy is required to be highly digitalized (the presence of the wide market for MOOC, the penetration of online learning and mobile learning, the use of new ways of interaction in the classroom, such as collaboration, STEM, etc.) On the part of the production sector, digital infrastructure, autonomy, robotization, the use of big data analytics and the ability to connect digital services of the training system to production services in one form or another are required [24], [34].

A number of researchers highlight that the problems of the integration of learning platforms and pedagogical activities into Industry 4.0 are characteristic of both developing and developed economies [24]. Moreover, most problems faced by developed economies in the field of production pedagogy are similar to those found in developing countries [25]. This is often due to generation changes and the emergence of new pedagogy focused on the whole new world view of native digitals [35], [36].

\section{Conclusion}

The need for the early formation of Industry 4.0 is associated with international competition, and training of highly qualified specialists for the new industry is a crucial factor in this process. The study assesses the readiness for the integration of pedagogical and production factors in the process of the formation of Industry 4.0 through the example of 226 students and 68 teachers of Russian State Vocational Pedagogical University, Ekaterinburg, Russia. The study revealed high digital readiness of students (4.24 according to the student assessment and 2.82 according to the teacher assessment on a 5point scale) and very low readiness of production to 
accept integrated learning (1.68 and 2.67, respectively), as well as the poor digitalization of the educational process according to the students and teachers, who are more closely familiar with the reality of production (2.03 and 2.45 , respectively). Students and teachers showed a low assessment of the readiness for the integration of pedagogy and production in the course of training Industry 4.0 specialists. The major reason for this is the illpreparedness of the production sector, which, according to students, is not ready from the technical perspective - in terms of the level of penetration of the digital environment into production and the use of integration to train personnel. At the same time, the readiness of the digital environment and the quality of its development have been assessed as high by the teachers and students. The relatively low (average, 3 out of 5) assessment of the parameters related to student knowledge and training are largely associated with the problems of integrating learning with production.

\section{References}

[1]. Xu, M., David, J. M., \& Kim, S. H. (2018). The fourth industrial revolution: Opportunities and challenges. International journal of financial research, 9(2), 90-95.

[2]. Song, Y. W., Herzog, M., Kreimeier, D., \& Bender, B. (2016). Prototype Of A New Learning Factory-An Educational Approach to Integrate Production and Product Development. In DS 84: Proceedings of the DESIGN 2016 14th International Design Conference (pp. 2101-2110).

[3]. Terano, H. J. R. (2019). Development of Integrated Curricula for the Master of Engineering Programs Using the CDIO Framework. International Journal of Engineering Pedagogy, 9(3).

[4]. Petrillo, A., De Felice, F., Cioffi, R., \& Zomparelli, F. (2018). Fourth industrial revolution: Current practices, challenges, and opportunities. Digital transformation in smart manufacturing, 1-20.

[5]. Yan, Y., Zheng, X., Wang, S., Yang, G., \& Zhang, J. (2019). A collaborative environmental education pattern of deepening the integration of production and education based on application-oriented undergraduate teaching: a case study in civil engineering (major of beibu gulf university). Ekoloji, 28(107), 4711-4718.

[6]. Poór, P., \& Basl, J. (2019). Readiness of companies in relation to industry 4.0 implementation. In 17th International Scientific Conference on Hradec Economic Days (pp. 1-13). Hradec Kralove.

[7]. Blasbichler, A. A., \& Vogt, M. (2020). Between and Beyond. The Course of a Life in the Realms of History of Education, General Pedagogy and Comparative Studies. Interview with Edwin Keiner. Espacio, Tiempo y Educación, 7(2), 235-247.
[8]. Danilaev, D. P., \& Malivanov, N. N. (2020). Technological education and engineering pedagogy. Education and Science, (22 (3)), 55.

[9]. Malott, C. S. (2016). History and education: Engaging the global class war. Peter Lang Inc., International Academic Publishers.

[10]. Ocaña, A. O. (2017). Epistemic configuration of pedagogy. Widespread trends in the history of education. Revista Historia de la Educación Latinoamericana, 19(29), 165-195.

[11]. Kellsey, D., \& Taylor, A. (2016). The LearningWheel: A model of digital pedagogy. Critical Publishing.

[12]. Bauer, H., Brandl, F., Lock, C., \& Reinhart, G. (2018). Integration of Industrie 4.0 in lean manufacturing learning factories. Procedia manufacturing, 23, 147-152.

[13]. Williams, B., \& Figueiredo, J. (2014). From academia to start-up: a case study with implications for engineering education. International Journal of Engineering Pedagogy (iJEP), 4(1), 24-31.

[14]. Perini, S., Luglietti, R., Margoudi, M., Oliveira, M., \& Taisch, M. (2018). Learning and motivational effects of digital game-based learning (DGBL) for manufacturing education-The Life Cycle Assessment (LCA) game. Computers in Industry, 102, 40-49.

[15]. Nunes, T. F. B., Terra, S. X., \& Medianeira, L. (2019). Integrator project: A conception of knowledge integration in a production engineering undergraduate course. Journal of Research \& Method in Education, 9(5), 70-83.

[16]. Probst, A., Schachinger, G., Kalteis, G., \& Fischer, A. (2019). New Technologies as a Driver for Business Success. International Journal of Engineering Pedagogy, 9(1).

[17]. Yongmei, L., \& Hong, Z. (2017). On the way of developing integration of production-learningdevelopment in school of engineering of Peking University. Journal of Higher Education, 9, 5.

[18]. Ma, P. Y., Wei, S. G., Wang, X. H., Sun, Y., \& Song, D. Q. (2018). Teaching reform of instrumental analysis experiment based on integration of production, learning, research and application. Chinese Journal of Chemical Education, 4, 6.

[19]. Li, F., Yang, J., Wang, J., Li, S., \& Zheng, L. (2019). Integration of digitization trends in learning factories. Procedia manufacturing, 31, 343-348.

[20]. Tvenge, N., \& Martinsen, K. (2018). Integration of digital learning in industry 4.0. Procedia manufacturing, 23, 261-266.

[21]. Richert, A., Shehadeh, M., Willicks, F., \& Jeschke, S. (2016). Digital Transformation of Engineering Education. International Journal of Engineering Pedagogy, 6(4).

[22]. Landmann, E., Stolz-Römmermann, J., \& Günther, T. (2020). Customer integration through virtual reality implementation: a SWOT analysis in the area of production systems. In Augmented Reality and Virtual Reality (pp. 253-266). Springer, Cham.

[23]. Berlese, E. (2016). Digital Manufacturing: Challenges And Opportunities for the Italian Industry. (Bachelor's thesis, Università Ca'Foscari Venezia). 
[24]. Dahlman, C., Mealy, S., \& Wermelinger, M. (2016). Harnessing the digital economy for developing countries. OECD Development Centre Working Papers, (334), 1.

[25]. Manda, M. I., \& Ben Dhaou, S. (2019, April). Responding to the challenges and opportunities in the 4th Industrial revolution in developing countries. In Proceedings of the 12th International Conference on Theory and Practice of Electronic Governance (pp. 244-253).

[26]. AlMunifi, A. A., \& Aleryani, A. Y. (2019). Knowledge and Skills Level of Graduate Civil Engineers Employers and Graduates' Perceptions. International Journal of Engineering Pedagogy, 9(1).

[27]. Baena, F., Guarin, A., Mora, J., Sauza, J., \& Retat, S. (2017). Learning factory: The path to industry 4.0. Procedia manufacturing, 9, 73-80.

[28]. Tvenge, N., Ogorodnyk, O., Østbø, N. P., \& Martinsen, K. (2020). Added value of a virtual approach to simulation-based learning in a manufacturing learning factory. Procedia CIRP, 88, 36-41.

[29]. Prigozhina, K. B., \& Trostina, K. V. (2017). Distance learning technology as a tool for competitive growth of educational programmes in universities. The Education and Science Journal, 19(5), 166-187. [in Russian].
[30]. Richert, A., Shehadeh, M., Willicks, F., \& Jeschke, S. (2016). Digital Transformation of Engineering Education. International Journal of Engineering Pedagogy, 6(4).

[31]. Ngu, H. J., Lee, M. D., \& Osman, M. S. B. (2020). Review on current challenges and future opportunities in Malaysia sustainable manufacturing: Remanufacturing industries. Journal of Cleaner Production, 123071.

[32]. Talbot, J., Costley, C., Dremina, M. A., \& Kopnov, V. A. (2017). A review of the basic elements, organizational and theoretical foundations of workbased learning (WBL) in the higher education. The Education and science journal, 19(6), 91-118.

[33]. Steinberg, V. E., Vakhidova, L. V., \& Gabitova, E. M. (2019). An Analysis of the Vocational-Educational Problematics for Substantiating Production Specialist Competencies. Education and science, 21(1), 59-81.

[34]. Anastasiadis, F., Tsolakis, N., \& Srai, J. S. (2018). Digital technologies towards resource efficiency in the agrifood sector: Key challenges in developing countries. Sustainability, 10(12), 4850.

[35]. Catalano, H., \& Catalano, C. (2016). Study on the Use of the Didactic Methodology in the Training of the Native Digital. In The 11th International Conference on Virtual Learning [ICVL 2016]. Retrieved at: http://c3. icvl. eu/papers2016/icvl/index. htm.

[36]. Galante, S., \& Weiss, D. (2020). Digital Pedagogy in International Courses. Kibbutzim College of Education. 